\title{
A centralidade das aglomerações metropolitanas na economia globalizada: fundamentos econômicos e possibilidades políticas*
}

The centrality of metropolitan agglomerations in the globalized
economy: economic foundations and political perspectives

Daniel Sanfelici

\section{Resumo}

Em que pese a infinidade de previsões sobre o iminente declínio da importância das grandes cidades, estas últimas mantêm-se como nós privilegiados do desenvolvimento econômico. Este artigo propõe uma discussão teórica sobre as forças econômicas que reiteram a centralidade da metrópole no processo de globalização e sobre as possibilidades e limites da ação política local. Na primeira parte, o artigo dedica-se a examinar os fundamentos econômicos da aglomeração espacial. Na segunda parte, discute como essas mesmas forças econômicas básicas, mediadas pela ação pública local, estruturam o espaço intraurbano. E, na terceira e última parte, discute as possibilidades abertas à ação pública local, ressaltando que, para ser eficaz, esta última deve ser concebida, ao mesmo tempo, como transescalar e multidimensional.

Palavras-chave: globalização; urbanização; proximidade espacial; desenvolvimento local.

\begin{abstract}
Despite the numerous predictions about the imminent decline in the importance of large cities, they continue to be key hubs of economic development. This articles aims to discuss the economic forces that keep the metropolis at the center of globalization, as well as prospects and limits for political action at the local level. In the first part, the paper discusses the economic foundations of spatial agglomeration. The second part looks into how these economic forces, mediated by local public action, structure intra-urban space. In the third and last part, the paper examines the possibilities open to local public action, underscoring that, in order to be effective, it has to be seen as simultaneously trans-scalar and multi-dimensional.
\end{abstract}

Keywords: globalization; urbanization; spatial proximity; local development. 


\section{Introdução}

Em julho de 2015, o governo chinês anunciou um plano ambicioso de consolidar, no nordeste do país, uma área metropolitana contínua entre Beijing e Tianjin, a $150 \mathrm{~km}$ da capital. Se o projeto tiver êxito - o que depende, entre outras coisas, de investimentos pesados em infraestrutura de transporte e o deslocamento de parte considerável da estrutura administrativa, atualmente concentrada na capital, para um ponto intermediário entre os dois polos -, a megalópole ostentará uma população próxima a 130 milhões de habitantes, ocupando uma área equivalente a seis vezes a cidade de Nova York (Johnson, 2015). Em que pesem as ambições superlativas do governo chinês para esse projeto, ele é apenas um entre outros planos recentes que parecem sinalizar para uma percepção aguçada, por parte das autoridades chinesas, acerca da conexão existente entre crescimento econômico e urbanização (Johnson, 2013). Esta última, longe de ser apenas o resultado passivo do primeiro, é cada vez mais reconhecida como seu motor indispensável, uma descoberta bem-vinda para um governo que aspira a manter um ritmo frenético de crescimento como peça de legitimidade de um sistema político autoritário. Não obstante todas as incertezas que envolvem projetos de tal porte, o ritmo acelerado de urbanização e o crescimento do número de metrópoles não estão circunscritos à China, tampouco são fruto de simples voluntarismo político; antes, trata-se de uma tendência clara na maior parte dos países, desenvolvidos ou em desenvolvimento, intervencionistas ou mais liberais.
Essa constatação de uma trajetória de urbanização acelerada e, no âmbito desta, uma importância inegável das metrópoles e megacidades, refuta um sem-fim de narrativas surgidas nos últimos decênios que, evocando as facilidades de comunicação e transporte engendradas pelas inovações tecnológicas, ponderavam que a proximidade espacial e, por conseguinte, a aglomeração da população em grandes centros urbanos haveriam perdido seu sentido econômico e social. No mínimo, o mundo haveria de caminhar para um processo de urbanização cada vez mais difuso, dominado por redes de pequenas e médias cidades fisicamente próximas e economicamente conectadas, a exemplo do que ocorre na Terceira Itália; em versões mais ousadas, a difusão do trabaIho a distância e as infinitas possibilidades de subcontratação viabilizadas pela comunicação em tempo real permitiriam formas de cooperação que diluiriam por completo a necessidade de copresença em um espaço de fluxos imateriais. Embora a primeira hipótese pareça mais plausível, a realidade é que não apenas a urbanização, mas a metropolização continua sendo um traço indelével da economia atual, o que suscita a necessidade de discutir, de uma parte, as forças que continuam a impelir esse crescimento ininterrupto das cidades e a reestruturação dos seus espaços e, de outra, as aberturas e possibilidades políticas existentes para direcionar esse crescimento para configurações mais desejáveis do ponto de vista social e ambiental.

Com isso em vista, este artigo procura refletir criticamente sobre as condicionantes econômicas subjacentes ao ressurgimento das cidades e às mudanças na estruturação 
espacial interna dos centros urbanos. Revisitando brevemente a literatura relativamente extensa sobre o processo de aglomeração e seus fundamentos econômicos, a primeira seção do artigo discute como o crescimento vertiginoso das grandes cidades repousa sobre um rol de vantagens econômicas colocadas em marcha pela proximidade espacial sob a forma de economias externas ou externalidades. A dinâmica de acumulação não é apenas responsável, contudo, por produzir níveis cada vez mais elevados de urbanização e de metropolização, mas igualmente por fomentar transformações de grande envergadura na estrutura espacial interna das cidades através da modificação dos usos do solo urbano. Visando lançar luz sobre esses processos, muitos dos quais francamente desfavoráveis ao acesso mais democrático à cidade, a segunda parte do artigo discute os principais interesses, agentes e forças envolvidos na produção do espaço da cidade e aponta como a entrada de novos agentes no circuito imobiliário colocou novas questões para a reflexão. Como ficará evidente nessas duas primeiras seções, o reconhecimento da importância desses processos e forças econômicas nas transformações em curso não significa, absolutamente, a adesão a uma concepção da economia enquanto um campo independente da prática social, operando exclusivamente de acordo com suas leis internas; antes, ressaltar-se-á o entrelaçamento inevitável dos processos e práticas ditas econômicas com as dimensões social e política. Por fim, na última seção, o artigo coloca em pauta os principais desafios que se perfilam no horizonte da gestão das metrópoles nos próximos anos, desafios estes que se revelam ainda mais urgentes nos países em desenvolvimento - desde problemas básicos de moradia e saneamento, passando por transporte, segregação e acesso desigual ao urbano, até os problemas ambientais que se avultam. Observa-se que avanços em muitos desses campos só podem ser obtidos através de um enfoque integral dos problemas em questão e de formas de cooperação territorial mais sofisticadas no âmbito da gestão das metrópoles e da elaboração e execução de políticas públicas.

\section{A vantagem das metrópoles: aglomeração e inovação}

Entre as profecias que, no auge dos anos 1990, o discurso otimista da globalização validava, estava a ideia de que as tecnologias da informação e de transporte levariam, em maior ou menor grau, à perda de importância ou dissolução do território como nexo fundamental de interação social. ${ }^{1}$ Para os economistas versados na teoria econômica ortodoxa, esse vaticínio se amparava na premissa de que a redução ininterrupta dos custos de transporte e de comunicação, ao propiciar maior fluidez na transferência dos fatores de produção, favoreceria inexoravelmente uma distribuição mais equitativa dos recursos no espaço, enfraquecendo gradativamente as forças gravitacionais que geram a polarização (Veltz, 2014). No tempo que transcorreu desde então, as evidências não pararam de se acumular no sentido oposto: se, por um lado, a globalização favoreceu efetivamente o comércio de longa distância e viabilizou, através das tecnologias da informação, práticas mais sofisticadas de coordenação global das estratégias empresariais, por outro, não eliminou a necessidade de proximidade 
territorial na organização das atividades econômicas. Antes, há indicativos de uma correlação robusta entre a integração econômica global e a aglomeração espacial em alguns poucos polos urbanos que concentram, cada vez mais, as atividades econômicas mais avançadas, articulando-se horizontalmente em uma rede de cidades que extrapola as fronteiras, e muitas vezes a capacidade de ação, dos estados-nação (Amin e Thrift, 1992; Sassen, 2000; Scott, 1998; Veltz, 2014). Um indicador ilustrativo dessa importância adquirida pela metropolização é o crescimento exponencial do número de megacidades no mundo - definidas como aglomerações com mais de 10 milhões de habitantes. Segundo relatório da ONU, em 1990 havia 10 megacidades no mundo, cifra que saltou para 28 em 2014. ${ }^{2}$ Esse número pode, além disso, ser uma subestimação da soma total: um relatório recente da Organização para a Cooperação e Desenvolvimento Econômico (OCDE) calculou em 15 o número de megacidades existentes apenas na China, 7 a mais do que as estimativas da ONU indicavam (cf. Krause-Jackson, 2015). Nem mesmo os graves e persistentes problemas sociais e ambientais que concentrações populacionais dessa dimensão costumam ocasionar parecem frear o ritmo de crescimento das metrópoles, sobretudo nos países em trajetória de crescimento econômico acelerado.

Extrapolando o registro meramente anedótico, é forçoso indagar quais são as causas desse surto de urbanização recente. Há pelo menos dois decênios, uma bibliografia vasta no campo da geografia econômica e da economia regional vem procurando oferecer respostas mais refinadas a essa interrogação, qualificando o debate a fim de suplantar explicações mais ou menos simplificadas em torno de noções como centro e periferia ou países desenvolvidos e subdesenvolvidos. A questão crucial é compreender por que e como certos polos de aglomeração atingem níveis de produtividade e inovação crescentes, distanciando-se, em termos de riqueza produzida e apropriada, das demais cidades e regiões. Muitas disputas surgiram em torno da resposta mais adequada a essas questões, mas há hoje um consenso de que as metrópoles gozam de uma série de vantagens de natureza cumulativa sob a forma de economias externas ou de aglomeração (Scott, 1988; 1998; 2006; Scott e Storper, 2007; Storper e Walker, 1989; Storper, 1997; Veltz, 2014; Bathelt, Malmberg e Maskell, 2004; Pecqueur, 2009). ${ }^{3}$ Estas últimas englobam fenômenos diversos que podem ser condensados, sob o risco de certa simplificação, em quatro principais: 1) o compartilhamento de infraestruturas físicas de alto custo e marcadas pela indivisibilidade; 2) as interdependências transacionais entre firmas de um mesmo segmento ou cadeia produtiva; 3 ) a formação de um mercado de trabalho denso, diversificado e especializado; e, finalmente, 4) a criação de um ambiente propício à circulação de ideias, ao aprendizado e à inovação. Esses diferentes incentivos à aglomeração não são mutuamente excludentes; antes, eles frequentemente se sobrepõem ou se articulam de modos complexos. Todavia, o peso ou a importância de cada um deles se altera ao capricho de mudanças tecnológicas, de mudanças regulatórias que favorecem ou inibem o comércio internacional e de novas formas de concorrência que emergem como reação a transformações no ambiente de negócios. Convém discorrer brevemente sobre cada um deles. 
A mais básica de todas as formas de economia de aglomeração é aquela que decorre do compartilhamento de um sistema de infraestruturas de suporte ao comércio e à indústria. Com efeito, uma série de infraestruturas básicas e fundamentais à acumulação industrial - como rodovias, ferrovias, portos, aeroportos, sistemas de telecomunicação, sistemas de esgoto, etc. - possui custos elevados e alto grau de indivisibilidade. Essa sensibilidade das infraestruturas às economias de escala diminui a viabilidade de dispersão das delas pelo território, principalmente em países com escassos recursos para serem investidos. Historicamente, portanto, o compartilhamento de infraestruturas de alto custo foi um dos impulsos primordiais para aglutinar as firmas em torno de polos de urbanização intensiva, e isto de maneira tanto mais exacerbada quanto mais limitados eram os recursos para investimento no ambiente construído.

Um segundo patamar de vantagens aglomerativas emerge como resultado da densidade e frequência das trocas efetuadas entre produtores independentes em um contexto de divisão social do trabalho. Recorrendo à teoria dos custos de transação de Ronald Coase e a seus desenvolvimentos posteriores em autores como Stigler e Williamson, Scott (1988; 2006) elabora uma teoria da aglomeração que tem por núcleo explicativo a busca das firmas por reduzir os custos de transação. Segundo esse autor, muitos setores industriais obtêm sua organização ótima na forma de sistemas de produção desintegrados verticalmente - ou seja, sistemas nos quais as diferentes etapas do processo de produção de um bem final são efetuadas por firmas independentes, unidas apenas por relações de mercado, em vez de unidades produtivas verticalizadas em que as diferentes etapas da produção e suas conexões são coordenadas por deliberação administrativa. A inclinação em favor de um determinado sistema de produção (no caso, menos verticalizado) responde a imperativos de eficiência que se relacionam com economias de escala - ou seja, qual escala de produção é mais apropriada para a fabricação de um determinado componente - e com os custos de transação - ou seja, os custos de obtenção de um insumo via mercado comparado com os custos de produzi-lo internamente, o que remete ao que se costuma designar por economias de escopo ou de variedade. A contribuição de Scott (1988) à teoria da organização industrial proposta por esses autores consiste em integrar a distância espacial como um componente essencial dos custos de transação. A proximidade espacial e a aglomeração aparecem, então, como produto de uma busca por maior eficiência através da redução dos custos de transação especificamente relacionados com a distância física. No entanto, como o próprio autor admite (Scott, 2006), mais do que apenas uma redução dos custos de transação associados à distância, a proximidade espacial entre produtores articulados em uma cadeia de valor possibilita reajustamento e reconfiguração céleres das relações de fornecimento (input-output), o que se revela particularmente vantajoso em um contexto de volatilidade da demanda e de inovações de produto recorrentes, como tem sido o caso do capitalismo nos últimos decênios. Em outras palavras, em um contexto de incerteza de mercado e da consequente necessidade de ajustar frequentemente o perfil da oferta para responder de modo adequado à evolução rápida e imprevisível da demanda, a aglomeração mitiga os riscos 
derivados da necessidade de encontrar novos fornecedores e insumos especializados.

Um terceiro nível de externalidades relacionadas à aglomeração surge da formação de um mercado de trabalho denso e diversificado. Aqui as vantagens emergem das facilidades de que gozam as empresas no momento de prospectar e de contratar novos empregados com qualificações especializadas para realizar funções específicas, minimizando o risco de não encontrar a mão de obra de que necessitam para responder à evolução dos mercados. Do ângulo do empregado, existência de um universo extenso e heterogêneo de empresas permite-lhe valorizar competências específicas, incentivando e justificando maior nível de qualificação e especialização (Scott e Storper, 2007; Scott, 2006; Puga, 2010). Esse incentivo à habitação em áreas aglomeradas é ainda mais contundente quando se trata de casais com qualificação elevada, visto que a probabilidade de ambos encontrarem inserção adequada no mercado de trabalho é significativamente maior em metrópoles do que em cidades menores (Veltz, 2012). É preciso, outrossim, levar em consideração, como outro fator de estímulo à aglomeração, que os trabalhadores localizados em uma área aglomerada têm maior probabilidade de exibir uma trajetória profissional de mobilidade entre empresas de um mesmo setor ou mesmo de setores diferentes. Essa mobilidade é, ao mesmo tempo, fonte de socialização - ou seja, fomenta a internalização, pelo trabalhador, dos ritmos, hábitos e práticas de trabalho dominantes na aglomeração em questão, induzindo o aumento da produtividade das empresas - e de circulação de aprendizado na medida em que, ao migrar de uma empresa para outra, o trabalhador leva consigo todo o know-how e a experiência adquiridos na empresa em que estava.

Indubitavelmente mais importante na atual fase do capitalismo, em que a concorrência entre empresas nos setores líderes da economia se baseia não mais apenas no preço final e sim, crescentemente, no conhecimento e na inovação (Storper, 1997; Veltz, 2014; Mouhoud e Plihon, 2009; Scott, 2014; Courlet e Pecqueur, 2013), a aglomeração está associada com um quarto efeito de externalidade positiva: a promoção do aprendizado. 0 ponto de partida para estabelecer essa relação entre aprendizado e aglomeração é o reconhecimento de que os caminhos que conduzem à inovação e ao progresso técnico não estão circunscritos à pesquisa e ao desenvolvimento realizado em laboratórios, separados do dia a dia da produção e da gestão dos negócios. Com efeito, se, no auge do período fordista, não era de todo equivocado destacar a forte separação entre o momento da concepção e o momento da execução como um dos traços marcantes da organização da produção (Veltz, 2014), nos segmentos tipicamente pós-fordistas a inovação aparece cada vez mais como resultado de processos interativos que ocorrem no seio de uma densa malha de relações cotidianas travadas entre profissionais de uma mesma firma e, mais amplamente, pertencentes a uma miríade de firmas que cooperam horizontalmente no interior de uma mesma cadeia produtiva (Veltz, 2014; Bathelt, Malmberg e Maskell, 2004; Malmberg, 1997). ${ }^{4}$ Essas relações envolvem a troca frequente de conhecimentos diversos, mormente de natureza tácita, que contribuem para solucionar toda sorte de problemas relacionados à organização da produção e que, mais amplamente, estimulam a experimentação de novas formas 
de organização do trabalho, o uso de novos equipamentos técnicos e a criação de novas linhas de produtos. A proximidade espacial desempenha aqui um papel indispensável (embora, deva-se frisar, jamais exclusivo) na medida em que gera um ambiente propício à inovação contínua através da troca constante de informação, ambiente este caracterizado pelo que Storper e Venables (2004) denominaram burburinho. Bathelt, Malmberg e Maskell (2004, p. 38) explicam que o burburinho:

[...] refere-se à ecologia de informação e comunicação criada pelos contatos face a face, pela copresença e pela colocalização das pessoas e firmas em uma mesma indústria e lugar ou região. Esse burburinho se compõe de informações específicas e contínuas atualizações dessas informações, processos intencionais ou não intencionais de aprendizado em encontros organizados ou acidentais, a aplicação dos mesmos esquemas interpretativos e entendimentos mútuos sobre novos conhecimentos e tecnologias, assim como tradições culturais e hábitos compartilhados em um domínio tecnológico particular, que estimulam o estabelecimento de convenções e outros arranjos institucionais. (Tradução nossa)

Por isso, uma vez que ganham forma, em uma região, convenções duradouras baseadas no que Storper (1997) denominou interdependências não comerciais (untraded interdependencies) entre os produtores, e instituições que, ao mesmo tempo, refletem e reproduzem as características fundamentais dessas convenções, o processo de aglomeração tende a se fortalecer como decorrência das vantagens competitivas geradas pelos processos de aprendizado. Algumas aglomerações passam, então, a exibir uma trajetória de crescimento acelerado e autossustentado através da especialização em um setor ou em um grupo de setores econômicos de destaque, crescimento este que lhes confere uma posição privilegiada na divisão territorial do trabalho. É assim que certas cidades vêm a adquirir reputação pelo domínio que exercem sobre as cadeias produtivas de alguns setores econômicos, como é o caso de Londres e Nova York nas finanças, São Francisco e o Vale do Silício na indústria de tecnologia da informação, Milão na moda e Paris na indústria farmacêutica, para citar apenas os exemplos mais conhecidos. É importante ressaltar, portanto, que as externalidades de aprendizado a que estamos aludindo não são um resultado mecânico dos automatismos de mercado, mas repousam sobre a capacidade de os agentes econômicos locais construírem instituições (formais e informais) e desenvolverem rotinas que fomentem a cooperação para o aprendizado de longo prazo, o que coloca em questão muitos dos modelos de desenvolvimento urbano e regional que dominam a agenda política das cidades (voltaremos a esse ponto adiante).

A persistência desse conjunto de mecanismos econômicos primários sustenta, portanto, as forças centrípetas de aglomeração que, por sua vez, promovem a aceleração do processo de urbanização na escala global, como o exemplo da China atual ilustra bem (Miller, 2012). A menos que transformações profundas ocorram no atual modelo de desenvolvimento econômico, a marcha da urbanização não deverá ser refreada e, menos ainda, revertida nos próximos decênios. Por isto, o urbano e a urbanização precisam estar no centro de qualquer reflexão acerca do desenvolvimento econômico e social e dos sentidos que lhes devem ser 
atribuídos. Em particular, parece inevitável hoje a conclusão de que a mobilização do potencial latente de cooperação no contexto da imensa diversidade de culturas, hábitos, concepções e habilidades que as cidades encerram é uma das chaves para repensar o desenvolvimento na atualidade. No entanto, antes de discutir essas questões relativas às possibilidades de intervenção política, convém colocar em pauta uma outra dimensão do processo urbano, a saber, as transformações do uso do solo urbano, os agentes que as promovem e suas consequências para os diferentes grupos e classes sociais que habitam as cidades.

\section{A mudança nos usos do solo urbano e a estrutura intraurbana}

As mesmas forças de atração gravitacional que, na escala do território, ocasionam a aglomeração da atividade econômica em concentrações urbanas de elevada densidade e grande extensão, condicionam algumas das características básicas da estrutura interna das cidades. 0 tecido intraurbano é marcado pela justaposição de uma gama extensa de usos do solo que conformam uma totalidade ao mesmo tempo altamente diferenciada e fortemente polarizada. Essa polarização reflete a procura das firmas e dos indivíduos nelas empregados por proximidade espacial, gerando pontos de maior densidade ocupacional que estruturam, grosso modo, a distribuição dos usos do solo (Scott, 2008). 0 acesso à proximidade espacial e às vantagens dela decorrentes é mediado, na economia capitalista, pela regulamentação dos direitos de propriedade e pela formação de um mercado no qual os proprietários negociam seus imóveis a um preço que reflete a capitalização do fluxo esperado de renda (na forma de aluguéis) que a cessão do uso da propriedade imobiliária pode Ihes proporcionar. Esse fluxo esperado de renda guarda estreita relação com o posicionamento (cambiante) de uma parcela do solo no tecido metropolitano. 0 princípio mais básico de estruturação do espaço urbano é, portanto, o da precificação da centralidade, o que explica que o gradiente de preços do solo urbano tenda a atingir seus patamares mais elevados nas proximidades dos pontos de maior concentração das atividades econômicas ou em locais onde o acesso a essas centralidades é facilitado pela existência de infraestruturas de transporte (Harvey, 2010; Scott, 1980) - o que não significa que outros princípios de estruturação do solo urbano não se façam igualmente presentes, como amenidades diversas que criam externalidades positivas.

Esse princípio básico de atribuição de um preço (renda) à centralidade pode ser vislumbrado nitidamente em operação quando um investimento realizado pelo Estado em uma nova linha de transporte metropolitano interliga pontos antes mal conectados com as áreas centrais da cidade, reposicionando as diferentes parcelas do tecido urbano no espaço relativo (Harvey, 1999). Um exercício hipotético permite ilustrar esse processo. Quando ocorre um investimento em uma nova rede de transporte ou a extensão de uma linha de transporte já existente, o solo urbano situado nas imediações de um novo terminal de transporte torna-se alvo de disputa entre potenciais usuários com fins residencial ou comercial em função do seu melhor posicionamento em relação às 
principais centralidades da metrópole. Essa disputa gera uma expectativa de preços futuros em ascensão que sinaliza, aos empreendedores imobiliários, uma oportunidade de ganhos com a oferta de imóveis novos na região. Os proprietários de imóveis ou terrenos na região são, então, confrontados com uma demanda crescente de firmas de incorporação e construção em busca de terrenos para construção. Se a disponibilidade de terrenos for limitada por se tratar de uma região já plenamente construída, os empreendedores imobiliários deverão adicionar, aos demais custos de um empreendimento, os custos de demolição das estruturas existentes e, com base nesse cálculo, decidir acerca da viabilidade do empreendimento. Com a expectativa de ganhos futuros validando os planos de investimento dos empreendedores imobiliários ocorrerá um gradativo adensamento ocupacional acompanhado de (maior ou menor) elevação dos preços imobiliários na localidade, alterando, por sua vez, o perfil socioeconômico dos moradores.

Se é inegável que a lógica da centralidade estrutura em grandes linhas a distribuição dos usos do solo urbano, a caracterização do processo de transformação nos usos do solo nos termos acima capta apenas parcialmente a realidade, porque supõe o triunfo irrestrito de uma racionalidade econômica pura em que os empreendedores apenas respondem cegamente aos estímulos gerados pela evolução da demanda. Em primeiro lugar, e de modo evidente, todas as decisões de transformação do uso do solo são mediadas por instituições e por marcos regulatórios, operantes em diversas escalas espaciais, que restringem ou direcionam a ação dos proprietários, dos investidores, dos empreendedores e dos usuários finais (Ball, 1983; Guy e Henneberry, 2000). Para permanecer com a ilustração precedente: se as leis de zoneamento da área adjacente ao novo terminal de transporte inibirem o adensamento e a verticalização, a elevação dos preços e, por conseguinte, a velocidade e intensidade das transformações serão sobremaneira limitadas. ${ }^{5} \mathrm{Em}$ segundo lugar, essa explicação focaliza (quase) exclusivamente o lado da demanda por espaço como determinante nas transformações que ocorrem nos usos do solo, atribuindo ao segmento imobiliário (e, portanto, à oferta) o papel eminentemente passivo de reagir aos sinais de preço gerados pelo crescimento e pelas preferências cambiantes da demanda - estas últimas condicionadas por forças macroeconômicas ou macrossociais, como a geração de empregos, para o caso da demanda das empresas, ou o aumento da renda, para o caso da demanda das famílias (Healey e Barrett, 1990; Healey, 1991; Gottdiener, 1994). No entanto, ainda que em um nível elementar, a demanda por novos imóveis responda a estímulos macroeconômicos variados, a natureza e a direção espacial das transformações imprimidas na escala local refletem igualmente as interações (muitas vezes conflituosas) entre uma gama heteróclita de agentes - proprietários de terras, incorporadores, investidores, bancos, agências de planejamento urbano, etc. - inseridos em um contexto de convenções, valores, instituições e rotinas de produção particulares ao território no qual operam. Dito de outra maneira, a simples existência de uma demanda não permite antever com precisão: 1) se essa demanda será atendida (no volume necessário) e com que rapidez, tendo em vista os inúmeros obstáculos de natureza regulatória e de coordenação que se interpõem aos agentes na produção de novos 
imóveis; e 2) como essa demanda será atendida, seja em termos de tipologias e qualidades de construção, seja em termos de localização. Depreende-se disso, entre outras coisas, que a reconfiguração dos usos do solo da cidade não deve ser interpretada apenas como uma reação do mercado imobiliário a variáveis que Ihe são exógenas, como a evolução da renda, o crescimento econômico, a mudança das preferências dos consumidores e a ampliação das infraestruturas de transporte, mas também, em boa medida, como um produto das decisões e apostas especulativas de empreendedores que, longe de agir isoladamente, fazem-no em um ambiente denso de interações, trocas de informação, crenças compartilhadas, alianças, etc. (Guy e Henneberry, 2000; Fainstein, 2001). É essa autonomia relativa da oferta em relação às circunstâncias econômicas que explica a capacidade de o setor imobiliário criar novas centralidades urbanas em localidades pouco evidentes do ponto de vista dos eixos estruturantes de uma metrópole, produzindo um redirecionamento do crescimento da cidade através da redistribuição dos grupos sociais no tecido urbano. ${ }^{6}$

0 enredamento do mercado imobiliário em contextos sociais, políticos e culturais de referência tem por corolário evidente que a morfologia espacial das cidades jamais é um reflexo de uma racionalidade econômica pura, como preconizam ou desejam algumas abordagens econômicas. ${ }^{7}$ Como assinala Haila (1988), as condições de exercício de uma racionalidade mais puramente econômica, que viabilizaria o tratamento do solo urbano como um ativo financeiro nos termos de Harvey (1999), nem sempre estão presentes e, mesmo quando estão, os agentes portadores dessa racionalidade devem disputar o espaço (social, mas também geográfico) com outras formas de conceber os benefícios aportados pela propriedade de imóveis. Ademais, raramente os habitantes de uma cidade aceitam passivamente o avanço da racionalidade econômica sobre formas alternativas de conceber, imaginar e organizar os usos e fluxos que perpassam o espaço urbano (Fainstein, 2001). Embora inúmeras disputas de moradores contra o adensamento e a construção de novos edifícios não sejam muito mais do que defesas de privilégios, bem sintetizadas no acrônimo inglês NIMBY, ${ }^{8}$ muitas outras são conduzidas por organizações e movimentos sociais com uma visão mais ampla de direito à cidade. São essas organizações que pressionam o poder público para intervir no sentido de impedir que 0 adensamento excessivo elimine os espaços públicos ou gere uma sobrecarga sobre a infraestrutura existente; para preservar o patrimônio histórico-cultural da cidade; para reivindicar o direito de grupos sociais mais vulneráveis permanecer em áreas mais centrais das cidades (seja mediante o investimento em novos projetos de moradia social, seja através da regularização e qualificação de assentamentos informais); ou para solicitar melhor acessibilidade das áreas mais empobrecidas aos centros de emprego e lazer através da ampliação da rede de transporte. A mercantilização do solo urbano e a rígida segregação dos grupos sociais no espaço que dela resulta não podem ser, portanto, vistas como um processo contínuo e inexorável, sem contradições e disputas que impõem avanços e recuos (voltaremos a esse ponto adiante).

Em síntese, a estrutura interna das cidades traduz, inegavelmente, os imperativos econômicos básicos de aglomeração e 
polarização, mas essas forças primárias são sempre mediadas e defletidas por normas, instituições, rotinas e convenções sociais que produzem resultados pouco previsíveis em termos socioespaciais - algo que um olhar comparativo superficial entre cidades tão diferentes como Amsterdã e Los Angeles, ou São Paulo e Buenos Aires, pode facilmente confirmar (Shatkin, 2007). Dito isto, é pertinente reconhecer que a entrada em cena de novos agentes na produção do espaço vem produzindo pressões em favor de um aprofundamento de uma racionalidade mais estritamente econômica na concepção e produção das cidades. Referimo-nos aqui à relevância que assumiram os ativos de base imobiliária nas estratégias de gestão de portfólio de agentes financeiros designados genericamente como investidores institucionais. Desde meados da década de 1980, sob o efeito triplo da desregulamentação e liberalização financeira iniciada com mais ímpeto nos Estados Unidos, das inovações no âmbito das tecnologias da informação e, finalmente, do redirecionamento da poupança privada, antes concentrada em depósitos bancários, para alternativas de investimento mais rentáveis como fundos de pensão e mutual funds, os investidores institucionais tornaram-se protagonistas das transformações profundas ocorridas na economia capitalista, muito além do domínio financeiro stricto sensu. São essas transformações de ampla envergadura nas estruturas básicas do capitalismo que uma literatura extensa, e em franco crescimento após a crise de 2008, procurou englobar com o conceito de financeirização (Braga, 1997; Orléan, 1999; Froud, Johal e Williams, 2002; Chesnais, 2002; Lapavitsas, 2009; Belluzzo, 2009). Não é nosso propósito aqui revisitar esse debate, mas antes assinalar um ponto de comum acordo entre a maioria dos autores, a saber, que um dos traços mais expressivos da ascensão das finanças globalizadas é seu afã de reduzir, para fins de comparabilidade imediata, todos os setores da economia a um denominador comum universal: sua capacidade de gerar valor para 0 acionista investidor. Esse apetite por rentabilidade se combina com estratégias de diversificação de ativos - tanto geográficas quanto setoriais - que prometem reduzir a exposição ao risco concentrado, compensando flutuações negativas em algum setor com ganhos mais expressivos em outro.

0 setor imobiliário emergiu, nesse contexto, como uma das alternativas de diversificação de investimento aos investidores institucionais, que podem obter exposição a essa "classe de ativos" (jargão comum no meio financeiro) por mais de uma via - por exemplo, a compra de ações ou de títulos privados emitidos por construtoras e incorporadoras; a aquisição direta de imóveis para locação a outras empresas, como edifícios corporativos nos distritos de negócios das cidades ou galpões logísticos situados próximos a entroncamentos rodoviários estratégicos; a aquisição de cotas de companhias imobiliárias ou fundos de investimento imobiliário; a compra de participação em shopping centers, etc. Conforme uma gama de pesquisas vem demonstrando, a entrada desses novos agentes no financiamento à atividade imobiliária acarretou mudanças importantes não apenas na organização interna do setor imobiliário, que em alguns países levou à consolidação de firmas de maior poder de mercado, mas também na própria maneira como esse setor produz as cidades (BoteIho, 2007; Fix, 2007; Shimbo, 2012; Theurillat, 
Corpataux e Crevoisier, 2010; Aalbers, 2008; David e Halbert, 2014; Halbert e Rouanet, 2014; Sanfelici e Halbert, 2016; Guironnet, Attuyer e Halbert 2015; Fields e Uffer, 2016). Em particular, a presença dos investidores financeiros introduziu temporalidades e espacialidades dissonantes no processo de produção das cidades, geralmente tributárias de um modo diferente de conceber rentabilidade e risco (Theurillat, Rérat e Crevoisier, 2015).

Três breves exemplos são suficientes para esclarecer esse ponto. Primeiro, no caso de ativos como edifícios de escritório, o movimento de externalização (venda) do patrimônio imobiliário por parte de empresas até então proprietárias-ocupantes, iniciado nos anos 1980 e justificado pelo anseio por maior flexibilidade operacional, tornou esses ativos imobiliários alvos preferenciais de investidores como fundos de pensão e veículos de investimento especializados, como os fundos de investimento imobiliário. Esses agentes investem seja adquirindo imóveis já existentes de firmas que desejam se desvencilhar de seu patrimônio imobiliário, seja adquirindo (e às vezes financiando) imóveis novos que lhes são ofertados por promotores imobiliários. As análises existentes sobre as estratégias de investimento desses investidores financeiros apontam para lógicas de seletividade pronunciadas que contribuem para a concentração geográfica dos investimentos imobiliários em um núcleo duro de metrópoles com vocação global e, dentro delas, em alguns poucos distritos de negócios consolidados. Essas lógicas possuem fundamentos diversos, mas frequentemente encontram explicação em noções de risco e retorno muito próprias às finanças de mercado, que levam os investidores a priorizar o investimento em cidades nas quais a liquidez dos ativos é mais elevada, ou seja, em que a densidade do mercado imobiliário local facilita tanto a revenda do ativo para reestruturação da carteira quanto a prospecção de um novo locatário na ocasião de uma rescisão ou término de contrato; e em que a percepção de risco é menor devido à familiaridade com o ambiente de negócios (Theurillat, Corpataux e Crevoisier, 2010; Henneberry e Mouzakis, 2014).

0 segundo exemplo refere-se à presença dos investidores como acionistas de empresas de construção e incorporação, um tema sobre o qual é instrutivo olhar para a evolução recente no Brasil. A partir de 2005, quando uma onda de investimento estrangeiro atingiu o segmento da construção e incorporação, um grupo de incorporadoras tirou proveito das condições de financiamento para adotar estratégias de expansão acelerada através da aquisição de outras empresas e da entrada em mercados regionais (Shimbo, 2012; Fix, 2011; Sanfelici, 2013). Essa estratégia de expansão acelerada, fruto de uma convenção coproduzida entre a comunidade financeira e a diretoria das construtoras de capital aberto, engendrou um encurtamento do horizonte temporal das empresas, cujo desempenho passou a ser mensurado, nos anos que sucederam à abertura de capital, cada vez mais de acordo com o aumento no volume de unidades lançadas de um trimestre para o outro, em detrimento de uma visão de mais longo prazo e multidimensional (Sanfelici e Halbert, 2016). Essa ênfase na capacidade de expansão das empresas teve como resultado, além de uma mudança decisiva na estrutura do setor devido à maior participação de mercado das incorporadoras de capital aberto, a multiplicação de grandes projetos imobiliários, como 
condomínios fechados e loteamentos denominados "bairros planejados", que fortaleceram um padrão fragmentado de produção do espaço nas grandes cidades (Sanfelici, 2013).

Por fim, convém sublinhar que os investidores financeiros se caracterizam pelo recurso a práticas de investimento pouco convencionais que permitem extrair o máximo de rendimento de um ativo imobiliário. Uma dessas práticas é a aquisição de imóveis na fase recessiva do ciclo de negócios, visando ganhos de capital de curto e médio prazo. Essa prática geralmente está acessível somente a grandes fundos de investimento que podem recorrer à alavancagem (contração de empréstimos) para maximizar os ganhos e já se faz presente na realidade brasileira com a entrada recente de grupos internacionais como Blackstone (Grant, 2015). À aquisição pode se seguir um projeto de renovação do ativo para adequá-lo às exigências das empresas ocupantes e, após a retomada do crescimento econômico, a revenda do ativo para outros investidores e a realização de expressivos ganhos de capital.

A participação mais ativa de investidores financeiros no circuito de financiamento da atividade imobiliária bem como o volume de recursos que esses agentes estão aptos a mobilizar sinalizam, portanto, para um avanço da racionalidade financeira que converte os ativos imobiliários em ativos financeiros comparáveis a outros títulos e obrigações (Harvey, 1999). Cada vez mais zonas urbanas percebidas como subaproveitadas do ponto de vista da geração de renda são reconvertidas a fim de possibilitar uma extração de renda compatível com a sua localização no tecido metropolitano. Essa pressão por capitalização financeira dos fluxos de rendimento urbano traduz-se, em muitos casos, em processos de valorização territorial que tornam mais difícil a presença de moradores de renda mais baixa e de pequenos comerciantes em áreas de acessibilidade urbana elevada, embora as repercussões concretas de projetos imobiliários ou planos de renovação urbana precisem ser estudadas caso a caso e não dedutivamente presumidas. ${ }^{9}$ De todo modo, esses novos agentes econômicos e as estratégias que acionam colocam importantes desafios para gerir as metrópoles, sobretudo de uma perspectiva que priorize as questões de justiça social e direito à cidade.

\section{Desafios futuros das metrópoles: reinventar o desenvolvimento local através de um enfoque transescalar e multidimensional}

Diante do quadro de transformações acima esboçado, em que forças econômicas abstratas parecem impor tanto um recrudescimento da metropolização em escala global quanto uma profunda reestruturação da morfologia interna das metrópoles, haveria ainda sentido em pensar (e exercer) a política na escala local? Ou, ao contrário, haveriam as interdependências tecidas pela globalização e a proeminência de agentes econômicos desterritorializados causado um esvaziamento da política nessa escala geográfica? E, finalmente, se a resposta para esta última indagação for negativa, que margem de manobra haveria restado aos governos locais? As reflexões elaboradas nos parágrafos acima, que sublinharam o caráter social e politicamente situado da economia capitalista e 
das trocas de mercado, sugerem, de imediato, uma resposta positiva à primeira interrogação. No entanto, entendemos que é preciso qualificar esse debate se se pretende pensar o desenvolvimento local e, sobretudo, nesse movimento, responder à terceira questão, sobre as margens de manobra na escala local.

Conforme argumentou Halbert (2016), duas formulações, em boa medida antagônicas, ganharam proeminência na reflexão sobre o papel dos governos locais no contexto da globalização. A primeira ressalta a fluidez e mobilidade dos atores econômicos ensejadas pela globalização da economia e propugna a implementação de políticas visando a atrair esses atores desterritorializados mediante a oferta de incentivos de natureza diversa, como investimentos em infraestrutura física e incentivos fiscais. Segundo essa concepção da política local, não restaria a esta última, portanto, senão adequar-se ao poder de mobilidade das grandes firmas e disputar com outras localidades a atração dessas firmas, na esperança de que a instalação de novos agentes exógenos possa gerar sinergias positivas em suas interações com outras firmas locais e, assim, impulsionar o crescimento econômico. A ideia de cidade criativa, inspirada pela teoria de Richard Florida, não seria muito mais do que uma variante desta última concepção, cujo foco é a atração, não de empresas, mas de indivíduos altamente qualificados para os centros urbanos através da melhoria de sua qualidade de vida (medida pela existência de espaços públicos, cosmopolitismo cultural, tolerância, etc.).

Uma vertente diferente desta última é aquela por alguns denominada novo regionalismo (Amin, 1999) ou localismo endógeno (Brandão, 2007), em suas diversas variantes. ${ }^{10}$
Ao contrário da concepção anterior, que vê a política local inteiramente à mercê do poder de fogo das maiores empresas e de sua incapacidade de estabelecer laços mais duradouros com as localidades, esta última concepção se inspira em boa parte na literatura, revisada no primeiro item deste artigo, que versa sobre as externalidades geradas pela copresença de atores econômicos organizados em cadeias produtivas locais. Para esta, a internacionalização das economias nacionais e a consequente perda de capacidade de coordenação econômica dos Estados nacionais haveriam alçado a escala local à linha de frente na política de desenvolvimento. Não se trataria, entretanto, de atrair investidores exógenos através da concessão de incentivos, mas de identificar os recursos latentes de uma região e potencializar sua mobilização através do incentivo à cooperação entre os agentes locais. Como enfatiza Halbert (2016), tratar-se-ia, aqui, de uma engenharia territorial "suave", baseada menos na oferta de ativos materiais do que no incentivo à mobilização e associação entre os atores econômicos.

Não é nosso objetivo, aqui, analisar criticamente essas duas vertentes (para isso, ver Halbert, ibid.), mas antes apontar dois aspectos que nos parecem essenciais para pensar o desenvolvimento local na atualidade, sobretudo se quisermos escapar de duas ilusões muitas vezes presentes na literatura sobre o desenvolvimento local: a de que o exercício da política nas demais escalas geográficas haveria perdido importância ou sentido na era da globalização; e a de que a política local deve focar-se no estímulo ao crescimento econômico, visto que meIhorias sociais e ambientais viriam naturalmente a reboque do crescimento. 0 primeiro deles 
consiste em reafirmar o lugar da política na escala local, mas, diferentemente da perspectiva dita localista, atentar para suas imbricações com outras escalas políticas, ou seja, pensar a política exercida na escala local como inserida em arranjos escalares mais complexos, que não podem ser ignorados nem suplantados pela pura vontade dos atores locais. Por isso, entendemos que uma política de desenvolvimento que se dirija ao local não pode perder de vista a complexidade escalar do Estado e da política. 0 segundo consiste em ressaltar que uma política de desenvolvimento urbano só merece essa denominação a partir do momento em que as diferentes dimensões do que se deveria considerar desenvolvimento estejam devidamente articuladas em um projeto de longo prazo.

Quanto ao primeiro ponto, que denominaremos transescalaridade da política urbana, ele decorre de pelo menos duas constatações importantes. A primeira refere-se ao fato de que a preeminência da escala local, mesmo nos casos de descentralização da gestão pública mais pronunciados, precisa ser, ainda assim, relativizada. Apesar da delegação de inúmeras responsabilidades administrativas às escalas de governo regional e local, em toda parte a escala nacional continua tendo um peso central na definição de algumas das diretrizes basilares do desenvolvimento social e econômico. Decisões importantes com respeito a aspectos tão diversos quanto a política de juros, a previdência social, a definição do salário mínimo, a destinação de verbas à saúde e à educação, a política comercial, o investimento em pesquisa e tecnologia, o investimento em grandes infraestruturas, entre inúmeros outros, continuam, em muitos países, sendo prerrogativa política dos governos centrais ou federais. Esperar que uma política de estímulo econômico implementada na escala local, segundo as linhas de ação propugnadas pelo modelo de desenvolvimento endógeno, seja o suficiente para desatar um ciclo de crescimento virtuoso significa ignorar a complexidade dos arranjos escalares nos quais está inserida a política local (Brandão, 2004; MacLeod e Goodwin, 1999; Brandão, 2007; Veltz, 2012; Amin, 1999).

Uma segunda constatação, relacionada à primeira e que fortalece a perspectiva de pensar a política local como inserida em arranjos escalares maiores, refere-se ao fato de que a importância adquirida pela escala local na gestão do desenvolvimento urbano não é apenas um corolário da reorganização da economia global, que haveria elevado esse nível escalar como aquele funcionalmente mais adequado para equacionar os problemas que entravam o desenvolvimento; na verdade, nos países em que a descentralização avançou de maneira mais rápida e consistente, isto ocorreu também como consequência da implementação de uma estratégia de reorganização do Estado que reflete um determinado projeto político hegemônico (Brenner, 1999; MacLeod, 2001). Isto significa, portanto, pensar a estrutura e organização (inclusive escalar) do Estado não como um produto direto de determinações econômicas advindas da globalização da economia, mas como um resultado (sempre temporário) de conflitos e disputas políticas em torno de um projeto hegemônico (Swyngedouw, 1997; MacLeod e Goodwin, 1999). ${ }^{11}$

Quais são as implicações, para a política urbana, que decorrem do reconhecimento da complexidade escalar da política e do Estado? Parece-nos essencial ressaltar, aqui, que qualquer projeto de desenvolvimento na escala 
urbana deve almejar a construção de vínculos de cooperação e alinhamentos de metas com outras escalas de administração política, visando à potencialização dos ganhos gerados por uma determinada política pública. É evidente que a construção desses vínculos entre escalas políticas não é apenas um problema de natureza técnica, visto que as relações entre escalas estão permeadas por relações de poder, e estas definem em grande medida em torno de quais políticas a convergência escalar será possível voltaremos a esse ponto das relações de poder. No entanto, é preciso frisar que a ausência de formas de coordenação interescalar na formulação e implementação das políticas urbanas resulta em toda sorte de disfuncionalidades e ineficiências que constituem importantes impedimentos para avanços imprescindíveis no âmbito do desenvolvimento urbano. A questão emergente da mobilidade urbana no Brasil, que esteve no centro dos protestos de 2013, ilustra bem a urgência de uma política de coordenação entre escalas. Embora inúmeros municípios tivessem envidado esforços genuínos, nos últimos anos, no sentido de aprimorar o sistema de transporte coletivo e, assim, abreviar o tempo de deslocamento diário entre moradia e trabalho, as políticas implementadas em nível federal de incentivo ao transporte individual motorizado e de financiamento subsidiado à aquisição da casa própria anularam todo e qualquer avanço que tivesse sido efetuado na escala local ou metropolitana (Maricato, 2011; Souza, 2013), deteriorando, sobremaneira, as condições de deslocamento de parte dos habitantes da cidade. A necessidade de ação transescalar é igualmente evidente em uma política de mitigação das desigualdades socioespaciais locais, e aqui novamente o caso brasileiro é rico em exemplos. É certo que existem inúmeras políticas e intervenções em nível local, muitas delas previstas no Estatuto da Cidade, que podem atenuar as desigualdades urbanas, como a definição de zonas especiais de interesse social, o uso do IPTU progressivo para coibir a especulação com terrenos em regiões providas de infraestrutura, a regularização e urbanização de favelas e a concessão de terrenos públicos ou a desapropriação de terrenos privados para fins de moradia social (para um rol desses instrumentos, ver Souza, 2001). Essas políticas e mecanismos devem ser reconhecidos em sua utilidade e devem ser empregados em todo seu potencial. No entanto, essas ações terão seus efeitos limitados ou mesmo dissolvidos enquanto o sistema tributário brasileiro, instituído em sua maior parte em âmbito federal, permanecer caracterizado por injustiças tributárias gritantes (Gondim e Lettieri, 2010), um ponto que muitos estudiosos do urbano soem ignorar. ${ }^{12}$

0 segundo ponto que merece atenção diz respeito à multidimensionalidade das políticas de desenvolvimento local, ou seja, à exigência de um reconhecimento mais explícito e reflexivo, pelos agentes políticos, das interdependências existentes entre as diferentes dimensões do fenômeno urbano como condição para a formulação de políticas públicas mais abrangentes e justas. Subjacentes a esse apelo estariam razões tanto de ordem normativa quanto de eficiência. No que tange à sua base normativa, a ideia de multidimensionalidade implica transcender uma visão de desenvolvimento local e regional que, a despeito de avanços, continua a colocar o acento sobre o crescimento do produto como indicador prioritário do progresso (Moulaert e Nussbaumer, 2005). 
Essa visão economicista, já há muito criticada por pensadores das mais variadas filiações teóricas, segue muito presente na literatura sobre desenvolvimento regional. Ora, se é verdade que não se pode conceber o desenvolvimento local e regional em um contexto de privação material aguda, como ocorre em muitos países do mundo em desenvolvimento, é também cada vez mais inegável que a noção de desenvolvimento extrapola em grande medida a mera elevação do produto e da renda. Com efeito, sabe-se hoje que este último não necessariamente garante direitos básicos, como o acesso à educação, ao saneamento básico, a condições ambientais salutares, ao atendimento médico, etc., benefícios que decorrem também de outros aspectos, como as disputas políticas em torno das prioridades de gasto público, o desenho das instituições, a qualidade da implementação das políticas, a distribuição da renda, etc. Em um plano mais pragmático, os avanços teóricos efetuados nos campos da geografia econômica, sociologia econômica e economia institucional, que colocaram em evidência o caráter social e culturalmente situado da economia (Amin, 1999; Peck, 2005), fornecem subsídios para uma política de desenvolvimento regional que tem na integração entre as diferentes dimensões do mundo social uma condição básica de eficiência da intervenção estatal. Com efeito, cada vez mais se reconhece que a robustez econômica das regiões se alicerça na qualidade e densidade dos elos que aproximam os diferentes agentes econômicos, suscitando um ambiente propício à confiança e à cooperação. A construção de vínculos de associação mais duradouros inclui, entre outras coisas, a criação e o fortalecimento de uma cultura de participação democrática e cidadã, através da instituição de fóruns de discussão e de acompanhamento das políticas públicas; a promoção de canais de diálogo e troca de conhecimento entre as empresas locais e exógenas visando a estimular a reflexividade, 0 aprendizado e a inovação; o combate às dinâmicas de segregação socioespacial que erigem barreiras (físicas e simbólicas) ao encontro de grupos sociais e culturais diferentes, um dos impulsos vitais da vida urbana. Trata-se, aqui, de apenas alguns exemplos que evidenciam o fato de que muitas das políticas frequentemente concebidas como pertencentes ao campo do social e do político são também componentes essenciais da vitalidade econômica da metrópole. Por isto, o horizonte de um urbanismo aberto (Halbert, 2010), que se oponha às tendências de fragmentação e segregação sempre presentes nas metrópoles, deve estar no centro das políticas de desenvolvimento local. Desnecessário frisar que, tal como a ideia de uma política multiescalar, a inclusão dessa perspectiva totalizante no planejamento urbano e regional é um ato essencialmente político, no sentido de que precisa confrontar uma gama de forças, interesses e setores econômicos que promovem e se beneficiam de um modelo de cidade e de política urbana de viés segregador.

\section{Considerações finais}

0 presente artigo procurou sintetizar, em grandes linhas, as principais forças econômicas que impelem o processo de urbanização e as mudanças territoriais urbanas no capitalismo atual. Observou-se, em primeiro lugar, que o motor básico da acumulação, impulsionado pela pressão competitiva em um ambiente 
econômico crescentemente global, exacerba a busca pela proximidade espacial por parte dos agentes econômicos, principalmente em função das vantagens competitivas que a aglomeração espacial engendra - o que contraria um leque variado de previsões surgidas no limiar da mais recente revolução tecnológica acerca da perda de importância da copresença no funcionamento básico da economia. São essas forças fundamentais que reorganizam a economia global em um extenso arquipélago composto de densas aglomerações urbanas interconectadas por redes (comerciais, informacionais, tecnológicas) de longa distância cada vez menos definidas ou controladas pelas fronteiras nacionais. Em um segundo momento, assinalamos que igualmente na escala local existem determinações econômicas fundamentais que moldam e reconfiguram incessantemente a distribuição dos usos do solo urbano, sobretudo em função da acessibilidade à principal (ou principais) centralidade da cidade. Contudo, como procuramos salientar, em especial no item precedente, essas forças econômicas não operam em um vácuo social, mas estão fortemente enraizadas em estruturas políticas, tradições culturais, instituições, convenções e redes de poder local. Por isso as transformações impressas pela globalização na escala local não devem ser vistas como o resultado de forças de mercado inexoráveis, às quais não restaria outra opção senão adaptar-nos (a famosa proposição neoliberal sobre não haver alternativa). Antes, há margem considerável de manobra para redirecionar o desenvolvimento econômico para arranjos mais favoráveis do ponto de vista da justiça social e ambiental. Para isso, como foi ressaltado, é necessária uma visão que tome em consideração tanto a complexidade escalar da política - o que permite escapar de um localismo ingênuo presente em parte da literatura sobre o ressurgimento das cidades e regiões - quanto a multidimensionalidade do desenvolvimento econômico.

Ressaltar as oportunidades de transformar as áreas metropolitanas em prol de um desenvolvimento econômico e social alternativo não significa, de forma alguma, ignorar o fato de que a política local está enredada em relações intricadas e multiescalares de poder (MacLeod, 2001). De uma parte, os governos locais precisam encontrar caminhos para forjar alianças com outras escalas de poder, que facilitam 0 acesso aos recursos (monetários, técnicos, operacionais, etc.) necessários para implementar ações na escala local. A existência de divergências políticas entre diferentes entes territoriais pode tanto dificultar o acesso a esses recursos, perturbando iniciativas potencialmente positivas, quanto, em casos mais extremos, bloquear por completo a possibilidade de capacidade de um governo local levar adiante um projeto político alternativo.

De outra parte, é evidente que, no âmbito local, a existência de visões arraigadas (e muitas delas francamente conservadoras) sobre o desenvolvimento local e a inércia que essas visões produzem opõem forças de monta para o avanço de projetos políticos mais progressistas. Em uma democracia, as divergências e as disputas políticas devem sempre ser decididas com base na construção de novos consensos que permitam agregar os cidadãos em torno de um projeto político mais amplo. A disputa acerca desses consensos está, todavia, sempre aberta. Por isso, a construção de uma política de desenvolvimento local alicerçada em uma visão 
mais progressista da cidade requer, antes de tudo, que as forças progressistas na sociedade civil elaborem um novo imaginário (e um novo vocabulário) político capaz de oferecer uma visão alternativa de cidade que seja coerente e que mobilize os diferentes grupos sociais.

\section{Daniel Sanfelici}

Universidade Federal Fluminense, Instituto de Geociências, Departamento de Geografia. Niterói, RJ/Brasil.

danielsanfelici@gmail.com

\section{Notas}

$(*)$ Este artigo é o resultado de reflexões desenvolvidas durante estágio de pós-doutorado no Laboratoires Techniques, Territoires et Sociétés (Université Paris-Est). Agradeço à Capes pelo financiamento ao estágio de pesquisa.

(1) Esse discurso não se circunscrevia aos debates no campo da economia, mas, em suas diferentes versões, estava presente nos principais debates das ciências humanas, como o atesta a prevalência do conceito de "desterritorialização" entre seus proponentes. Cf. Haesbaert (2004).

(2) Cf. http://www.un.org/en/development/desa/news/population/world-urbanizationprospects-2014.html.

(3) A profusão de pesquisas explorando a relação entre aglomeração e desempenho econômico foi precedida, no período pós-guerra, por teorias de economistas como François Perroux, Albert Hirschman e Gunnar Myrdal. Apesar do pioneirismo desses autores, a questão ficou em grande medida submersa diante de outros temas que eram considerados mais importantes, como as relações entre países desenvolvidos e subdesenvolvidos ou entre centros e periferias, na arena internacional (Scott, 2002).

(4) Sobre isto, Veltz (2014) afirma que "é na interorganização [...] que se constroem as competências e que se definem, em grande parte, os avanços técnicos. O 'progresso técnico' é, ao mesmo tempo, cada vez mais endogeneizado na economia mercantil e submetido às suas leis, e mais dependente de processos cooperativos e socializados" (p. 190, tradução nossa).

(5) Pode-se presumir, como muitos o fazem, que os interesses de alguma fração de classe ou setor econômico ou, ainda, e de maneira mais abstrata, do capital serão determinantes na formulação das leis de uso e ocupação do solo. Existem, evidentemente, muitos exemplos para confirmar tal assertiva. Entretanto, existem inúmeros outros exemplos em que, no embate entre proprietários e construtoras, os primeiros acabam por impor suas preferências, sobretudo quando são proprietários de alta renda. 
(6) Essa capacidade endógena do mercado imobiliário de redefinir, em um contexto de expectativas e crenças partilhadas entre os empreendedores privados, a distribuição dos usos do solo na cidade levou Abramo (2001 e 2012) a desenvolver uma análise da produção da cidade baseada na economia das convenções.

(7) Em edição recente, a revista The Economist, tradicional porta-voz do liberalismo econômico, lamentou a persistência de limitações ao aproveitamento do solo urbano em cidades como São Francisco e calculou que o PIB americano seria em torno de $13 \%$ mais elevado caso essas restrições fossem suprimidas. Em que pese a estreita redução do bem-estar social à dimensão do PIB que uma proposição desse tipo carrega, mesmo essa revista reconhece que, levada ao limite, a racionalidade econômica destruiria o que as cidades têm de melhor.

(8) Not In My Back Yard, que traduz a ideia do típico morador de renda média e alta que é indiferente ao adensamento e à construção, desde que não ocorram no seu bairro.

(9) Justamente porque, como procuramos discutir nos parágrafos anteriores, as reivindicações da sociedade civil podem, em muitos casos, frear os efeitos mais negativos da valorização imobiliária ou modificar projetos de renovação urbana para contemplar interesses diversos.

(10) Muitos autores fazem vista grossa às nuances e gradações existentes entre autores muitas vezes classificados como pertencentes a uma mesma vertente teórica, o que acaba por empobrecer o debate.

(11) Essa concepção estratégica do Estado, inspirada no trabalho de Bob Jessop, está bem sintetizada no texto de MacLeod e Goodwin (1999).

(12) É possível mesmo conjeturar que uma reforma tributária que corrigisse as distorções regressivas do atual sistema tributário brasileiro poderia ter efeitos mais profundos sobre o acesso à habitação do que uma política de subsídios à aquisição da casa própria.

\section{Referências}

AALBERS, M. B. (2008). The financialization of home and the mortgage market crisis. Competition \& change, v. 12 , n. 2, pp. 148-166.

ABRAMO, P. (2001). A cidade caleidoscópica. Rio de Janeiro, Bertrand Brasil.

(2012). La ciudad com-fusa: mercado y producción de la estructura urbana en las grandes metrópolis latino-americanas. Revista Eure, v. 38, n. 114, pp. 35-69.

AMIN, A. (1999). An institutionalist perspective on regional economic development. International journal of urban and regional research, v. 23, n. 2, pp. 365-378.

AMIN, A. e THRIFT, N. (1992). Neo-Marshallian Nodes in Global Networks. International journal of urban and regional research, v. 16, n. 4, pp. 571-587.

BALL, M. (1983). Housing policy and economic power: the political economy of owner occupation. Londres, Routledge. 
BATHELT, H., MALMBERG, A. e MASKELL, P. (2004). Clusters and knowledge: local buzz, global pipelines and the process of knowledge creation. Progress in human geography, v. 28, n. 1, pp. 31-56.

BELLUZZO, L. G. M. (2009). Os antecedentes da tormenta: origens da crise global. São Paulo, Editora da Unesp.

BOTELHO, A. (2007). O urbano em fragmentos: a produção do espaço e da moradia pelas práticas do setor imobiliário. São Paulo, Annablume.

BRAGA, J. C. S. (1997). "Financeirização global: o padrão sistêmico de riqueza do capitalismo contemporâneo". In: FIORI, J. L. (org.). Poder e dinheiro: uma economia política da globalização. Petrópolis, Vozes, pp. 195-242.

BRANDÃO, C. (2004). Teorias, estratégias e políticas regionais e urbanas recentes: anotações para uma agenda de desenvolvimento territorializado. Revista Paranaense de Desenvolvimento, n. 107, pp. 57-76.

(2007). Território e desenvolvimento: as múltiplas escalas entre o local e o global. Campinas, Editora da Unicamp.

(2011). Teorias, estratégias e políticas regionais e urbanas recentes: anotações para uma agenda do desenvolvimento territorializado. Revista Paranaense de Desenvolvimento-RPD, n. 107, pp. 57-76.

BRENNER, N. (1999). Globalisation as reterritorialisation: the re-scaling of urban governance in the European Union. Urban studies, v. 36, n. 3, pp. 431-451.

CHESNAIS, F. (2002). A teoria do regime de acumulação financeirizado: conteúdo, alcance e interrogações. Economia e Sociedade, v. 11, n. 1, pp. 1-44.

COURLET, C. e PECQUEUR, B. (2013). L'économie territoriale. Grenoble, Presses Universitares Grenoble.

DAVID, L. e HALBERT, L. (2014). Finance capital, actor-network theory and the struggle over calculative agencies in the business property markets of Mexico City Metropolitan Region. Regional Studies, v. 48, n. 3, pp. 516-529.

FAINSTEIN, S. (2001). The city builders: property development in New York and London, 1980-2000. Lawrence, Kansas, University Press of Kansas.

FIELDS, D. e UFFER, S. (2016). The financialisation of rental housing: A comparative analysis of New York City and Berlin. Urban Studies, v. 53, n. 7, pp. 1486-1502.

FIX, M. (2007). São Paulo cidade global: fundamentos financeiros de uma miragem. São Paulo, Boitempo Editorial.

(2011). Financeirização e transformações recentes no circuito imobiliário no Brasil. Tese de Doutorado. Campinas, Universidade Estadual de Campinas.

FROUD, J.; JOHAL, S. e WILLIAMS, K. (2002). Financialisation and the coupon pool. Capital \& Class, v. 26, n. 3, pp. 119-151.

GONDIM, F. e LETTIERI, M. (2010). Tributação e desigualdade. Le Monde Diplomatique Brasil.

GOTTDIENER, M. (1994). The social production of urban space. Austin, University of Texas Press.

GRANT, P. (2015). Desaceleração leva investidores à caça de pechinchas imobiliárias no Brasil. Valor Econômico. Disponível em: <http://www.valor.com.br/impresso/wall-street-journal-americas/ desaceleracao-leva-investidores-caca-de-pechinchas-imobiliaria>. Acesso em: 6 maio. 
GUIRONNET, A.; ATTUYER, K. e HALBERT, L. (2015). Building cities on financial assets: The financialisation of property markets and its implications for city governments in the Paris city-region. Urban Studies, v. 53, n. 7, pp. 1442-1464.

GUY, S. e HENNEBERRY, J. (2000). Understanding urban development processes: integrating the economic and the social in property research. Urban Studies, v. 37, n.13, pp. 2399-2416.

HAESBAERT, R. (2004). O mito da desterritorialização: do "fim dos territórios" à multiterritorialidade. Rio de Janeiro, Bertrand Brasil.

HAILA, A. (1988). Land as a financial asset: theory of urban rent as a mirror of economic transformation. Antipode, v. 20, n. 2, pp. 79-101.

HALBERT, L. (2010). L'avantage métropolitain. Paris, PUF.

(2016). As duas opções metropolitanas das políticas de desenvolvimento territorial. GEOgraphia, v. 18, n. 36, pp. 10-25.

HALBERT, L. e ROUANET, H. (2014). Filtering risk away: global finance capital, transcalar territorial networks and the (un) making of city-regions: an analysis of business property development in Bangalore, India. Regional Studies, v. 48, n. 3, pp. 471-484.

HARVEY, D. (1999). The limits to capital. Nova York, Verso.

(2010). Social justice and the city. Athens, Georgia, The University of Georgia Press.

HEALEY, P. (1991). Models of the development process: a review. Journal of Property Research, n. 8, pp. 219-238.

HEALEY, P. e BARRETT, S. M. (1990). Structure and agency in land and property development processes: some ideas for research. Urban studies, v. 27, n. 1, pp. 89-103.

HENNEBERRY, J. e MOUZAKIS, F. (2014). Familiarity and the determination of yields for regional office property investments in the UK. Regional Studies, v. 48, n. 3, pp. 530-546.

JOHNSON, I. (2013). China's great uprooting: moving 250 million into cities. New York Times. Disponível em: <http://www.nytimes.com/2013/06/16/world/asia/chinas-great-uprooting-moving-250million-into-cities.html>. Acesso em: 15 jun.

(2015). As Beijing becomes a supercity, the rapid growth brings pain. New York Times. Retrieved from. Disponível em: <http://www.nytimes.com/2015/07/20/world/asia/in-china-a-supercityrises-around-beijing.html?_r=0>. Acesso em: 19 jul.

KRAUSE-JACKSON, F. (2015). China has even more megacities than you thought. Bloomberg Business. Disponível em: <http://www.bloomberg.com/news/articles/2015-04-20/there-are-even-moremegacities-in-china-than-you-thought>. Acesso em: $20 \mathrm{abr}$.

LAPAVITSAS, C. (2009). Financialised capitalism: crisis and financial expropriation. Historical Materialism, v. 17, n. 2 , pp. 114-148.

MACLEOD, G. (2001). New regionalism reconsidered: globalization and the remaking of political economic space. International journal of urban and regional research, v. 25, n. 4, pp. 804-829.

MACLEOD, G. e GOODWIN, M. (1999). Space, scale and state strategy: rethinking urban and regional governance. Progress in Human Geography, v. 23, n. 4, pp. 503-527.

MALMBERG, A. (1997). Industrial geography: location and learning. Progress in Human Geography, n. 21 , v. 4, pp. 573-582. 
MARICATO, E. (2011). O impasse da política urbana no Brasil. Petrópolis, Vozes.

MILLER, T. (2012). China's urban billion: the story behind the biggest migration in human history. Londres, Zed Books.

MOUHOUD, E. e PLIHON, D. (2009). Savoir et finance: liaisons dangereuses au coeur du capitalisme contemporain. Paris, La Découverte.

MOULAERT, F. e NUSSBAUMER, J. (2005). The social region beyond the territorial dynamics of the learning economy. European urban and regional studies, v. 12, n. 1, pp. 45-64.

ORLÉAN, A. (1999). Le pouvoir de la finance. Paris, Odile Jacob.

PECK, J. (2005). Economic sociologies in space. Economic Geography, v. 81, n. 2, pp. 129-175.

PECQUeUR, B. (2009). A guinada territorial da economia global. Política \& Sociedade, v. 8, n. 14, pp. 79-106.

PUGA, D. (2010). The magnitude and causes of agglomeration economies. Journal of Regional Science, v. 50 , n. 1 , pp. $203-219$.

SANFELICI, D. (2013). Financeirização e a produção do espaço urbano no Brasil: uma contribuição ao debate. EURE. Santiago, v. 39, n. 118, pp. 27-46.

SANFELICI, D. e HALBERT, L. (2016). Financial markets, developers, and the geographies of housing in Brazil: a supply-side account. Urban Studies, v. 53, n. 7, pp. 1465-1485.

SASSEN, S. (2000). The global city: strategic site/new frontier. American Studies, v. 41, n. 2/3, pp. $79-95$.

SCOTT, A. J. (1980). The urban land nexus and the state. Londres, Pion.

(1988). Metropolis: from the division of labor to urban form. Los Angeles, University of California Press.

(1998). Regions and the world economy. Oxford, Oxford University Press.

(2002). Regional push: towards a geography of development and growth in low and middleincome countries. Third World Quarterly, v. 23, n. 1, pp. 137-161.

(2006). Geography and Economy. Oxford, Oxford University Press.

(2008). Inside the city: on urbanisation, public policy and planning. Urban Studies, v. 45, n. 4, pp. 755-772.

(2014). Metrópole ressurgente: economia, sociedade e urbanização em um mundo interconectado. GEOgraphia, v. 16, n. 32, pp. 8-37.

SCOTT, A. J. e STORPER, M. (2007). Regions, globalization, development. Regional Studies, v. 41, pp. 191-205.

SHATKIN, G. (2007). Global cities of the South: Emerging perspectives on growth and inequality. Cities, v. 24, n. 1 , pp. 1-15.

SHIMBO, L. Z. (2012). Habitação social de mercado. Belo Horizonte, C/Arte.

SOUZA, A. B. (2013). Presos no círculo, prostrados no asfalto: tensões entre o móvel e o imóvel. Tese de Doutorado. São Paulo, Universidade de São Paulo.

SOUZA, M. J. L. (2001). Mudar a cidade: uma introdução crítica ao planejamento e à gestão urbanos. Rio de Janeiro, Bertrand Brasil. 
STORPER, M. (1997). The regional world: territorial development in a global economy. Nova York, Guilford Press.

STORPER, M. e VENABLES, A. J. (2004). Buzz: face-to-face contact and the urban economy. Journal of economic geography, v. 4, n. 4, pp. 351-370.

STORPER, M. e WALKER, R. (1989). The capitalist imperative: territory, technology, and industrial growth. Nova York, Blackwell.

SWYNGEDOUW, E. (1997). "Neither global nor local: 'glocalisation' and the politics of scale". In: COX, K. (ed.). Spaces of globalization: reasserting the power of the local. Nova York/Londres, Guilford/ Longman.

THEURILLAT, T., CORPATAUX, J. e CREVOISIER, O. (2010). Property sector financialization: the case of Swiss pension funds (1992-2005). European Planning Studies, v. 18, n. 2, pp. 189-212.

THEURILLAT, T., RÉRAT, P. e CREVOISIER, O. (2015). The real estate markets: Players, institutions and territories. Urban Studies, v. 52, n. 8, pp. 1414-1433.

VELTZ, P. (2012). Des lieux et des liens: essai sur les politiques du territoire à l'heure de la mondialisation. Paris, L'Aube.

(2014). Mondialisation, villes et territoires: une économie d'archipel. Paris, Presses Universitaires de France.

Texto recebido em 25/jan/2016

Texto aprovado em 29/jun/2016 